\title{
Gross and Microscopic Anatomy of the Olfactory Bulbs in the Chinchilla (Chinchilla lanigera)
}

\author{
Irina IRIMESCU ${ }^{1 *}$, Pompei F. BOLFÄ ${ }^{2}$, Melania I. CRIŞAN ${ }^{1}$, Cristian C. DEZDROBITU ${ }^{1}$, Aurel DAMIAN ${ }^{1}$ \\ ${ }^{1}$ Department of Comparative Anatomy. University of Agricultural Sciences and Veterinary Medicine, Calea \\ Mănăștur nr. 3-5, 400372, Cluj-Napoca, Romania. \\ ${ }^{2}$ Department of Biomedical Sciences. Ross University, School of Veterinary Medicine, P.O. Box 334, \\ Basseterre, St. Kitts, West Indies. \\ *Corresponding author: irina.irimescu@yahoo.com
}

Bulletin UASVM Veterinary Medicine 72(2) / 2015,

Print ISSN 1843-5270; Electronic ISSN 1843-5378

DOI:10.15835/buasvmcn-vm: 11502

\begin{abstract}
Chinchillas are primarily used as laboratory animals in auditory pathways research, it is necessary to acquire detailed neuroanatomical data on other encephalon segments, in order to assess whether this species might also contribute as olfactory pathways experimental models. Thus, our research focused on providing a gross and microscopic description of the chinchilla's olfactory bulbs. Five chinchilla encephalon samples were harvested from commercially slaughtered young adults. The pairs of olfactory bulb were isolated by dissection, macroscopically examined while still attached, then detached, fixed in buffered formalin, serially cut and stained using a modified Luxol-Cresyl protocol. Gross and microscopic features were assessed and compared to literature descriptions of related species such as the rat and the rabbit. Chinchillas presented large olfactory bulbs with an average maximal diameter of $3 \mathrm{~mm}$ each, positioned in two corresponding deep grooves of the cribriform plate, orally to the anterior limit of the cerebral hemispheres. They decreased in girth ventro-aborally towards their base, which was located on the ventral side of the telencephalon. Histologically, they presented a laminar structure: an olfactory nerve layer, a glomerular layer, an external plexiform layer, a mitral cell layer, an internal plexiform layer and a granule cell layer. The proportionally well developed olfactory bulbs and the existence of the accessory olfactory bulbs demonstrates that $C$. lanigera is a macrosmatic species. The olfactory bulbs in the chinchilla present the gross anatomy and histological outline concurring with literature rodent descriptions, with certain particularities (accessory bulb topography, olfactory ventricle topography, glomerular size and shape).
\end{abstract}

Keywords: Chinchilla lanigera, gross anatomy, histology, olfactory bulbs

\section{INTRODUCTION}

Chinchillas are exotic pets originating from South American feral rodents (Mohlis, 1983; Spotorno et al., 2004). They became know at first as fur animals and they are, in fact, still bred throughout the world for this purpose (Alworth and Harvey, 2012; Jimenez, 1996; StekeloromParmelat, 2006).

Chinchilla lanigera is also used as a laboratory species in areas including neurological and auditory (Martin, 2012) fields of research. This started out by remarking the species' anatomical curiosities, such as an easy access to the middle ear due to its three chambered tympanic bulla
(Bennet, 1835 cited by Spotorno et al., 2004), but has evolved to developing experimental models linked to auditory pathology, due to this specie's particularities, such as: structural cochlear traits similar to humans and high resistance to ear infections as presented by Hrapkiewich et al. (1998), better human-like audiogram that in the rats, as demonstrated by Heffner and Heffner (1991). Separate from literature indicating its experimental uses in the aforementioned field (Brent, 2012; Guan et al., 2014; Jackson and Relkin, 1998; Krauss et al., 2013; Zhong et al., 2014), there is a growing interest in other possible experimental application of this species, leading to 
deeper studies of both its gross and its molecular neuroanatomy (Eggermont, 2015; Godfrey et al., 2005; Frisina et al., 1995; Irimescu et al., 2012; Irimescu et al., 2014a; Irimescu et al., 2014b; Jaworska-Adamu and Szalak, 2009; Szalak and Jaworska-Adamu, 2011).

The olfactory bulbs are one of the cerebral segments researched on laboratory rodents. While traditionally defined as "the first relay of the olfactory pathways" (Barone and Bortolami, 2004), current studies indicate that they hold other functions as well, such as "functional circadian peacemaker" in pre-visual rabbit cubs (Montufar-Chaveznava et al., 2012). They are involved in multiple research topics such as toxicity prevention studies (Mousa et al., 2015), developing new tools for Alzheimer's disease diagnosis (Qing Liu et al., 2013) and correlation studies of idiopathic Parkinson's disease (Shun Chen et al., 2013).

While chinchillas are primarily used for auditory pathways research, in view of the aforementioned potential revealed in laboratory rodents, it is necessary to acquire descriptive neuroanatomical data on its other encephalon segments, to help researchers in the field assess whether this species might also contribute as olfactory pathways experimental models. Thus, our research focused on providing a gross and microscopic description of the chinchilla's olfactory bulbs.

\section{MATERIALS AND METHODS}

The research was carried out using five pairs of chinchilla olfactory bulbs. The samples were harvested from commercially slaughtered young adults of both sexes. The pairs of olfactory bulbs were isolated by dissection using a standard dissection kit.

First, the skin and soft tissue were detached off the isolated head, and then the encephalon was exposed by carefully cutting the auditory bullae, the occipital, parietal and frontal bones with the aid of small bone cutter, following a horizontal plane of the maximal contour of the cerebral cavity. Immediately after the initial exposure of the encephalon, the samples were immersed in a buffered formalin solution for approximately one hour, to enable the nervous tissue to fixate and to be easier to isolate intact.
The olfactory bulbs were then completely exposed by detaching the anterior segment of the frontal bones. We have noted that great care must be taken at this point not to exert too much pressure on the osseous wall, which might let the tip of the cutter slip into either the olfactory fossa of the cerebral cavity and damage the nervous tissue.

After noting the topography of the olfactory bulbs in situ, we incised the cribriform plates along with fascicles of the olfactory nerves and of the others cranial nerves and thus detached the whole encephalon, extracting the olfactory bulbs along with it.

After macroscopic examination under an anatomical binocular lens, the samples were fixated in buffered formalin and histologically processed. They were embedded in paraffin, serially cut in coronal sections and stained using a modified Luxol Fast Blue - Cresyl Violet protocol, in order to highlight the nervous structures. The slides were examined with a standard light microscope and digitally photographed.

Both macroscopic and microscopic features were assessed and compared to literature descriptions of the same structure in related species - the rat and the rabbit. Macrocopical measurements were perfomed with an electronic caliper and histological images measurements were performed with the image software. As this study was performed on a limited sample group and had a qualitative focus, the values presented here are orientative and have not beent the object of a statistical analysis.

\section{RESULTS AND DISCUSSION}

Examining the olfactory bulbs in situ before extraction revealed that they are located in a deep olfactory fossa clearly separated from the cranial cavity by an internal circular indentation (Fig. 1). They were placed orally to the anterior limit of the frontal lobes of the cerebral hemispheres, covered by the anterior segment of the frontal bones. Their topography made their extraction difficult and necessitated a careful clipping of the osseous walls.

All chinchilla olfactory bulbs samples had a considerable volume, presenting the apparent origin of the olfactory nerve fascicles on their anterior surface and being continued by the usual olfactory structures: a short peduncle and 
two striae, out of which only the lateral one is clearly visible (Fig. 2). This elements correspond to previous observations (Irimescu et al., 2014c). Their maximal a transverse diameter measured approximately $3 \mathrm{~mm}$ and their length, approximately $6 \mathrm{~mm}$ (on the lateral approach).

Each medial side of two bulbs forming a pair was in close contact with its heterolateral congener (Fig. 1), though the bulbs and their peduncles were completely separated, each individually attached to the corresponding ventral side of the corresponding cerebral hemisphere (Fig. 3).

When viewed from the ventral side, in all samples there was a clear delimitation between each bulb and the corresponding peduncle, by means of an oblique medio-aboral groove that also corresponds to the final aboral narrowing of the bulb (Fig. 3).

The delimiting groove between the bulb and the peduncle was also very prominent on the medial side, so that the affronted indentations of each pair formed a small rhomboid shaped inter bulbo-peduncular space (Fig. 3).

The oral pole of the bulbs presented the olfactory fascicles and in four out of the five samples, small pieces of the cribriform plates still attached (Fig. 2). The insertions of the olfactory fascicles were also visible on the anterior half of the ventral side of the bulbs, while the lateral side of the bulbs was smooth and convex.

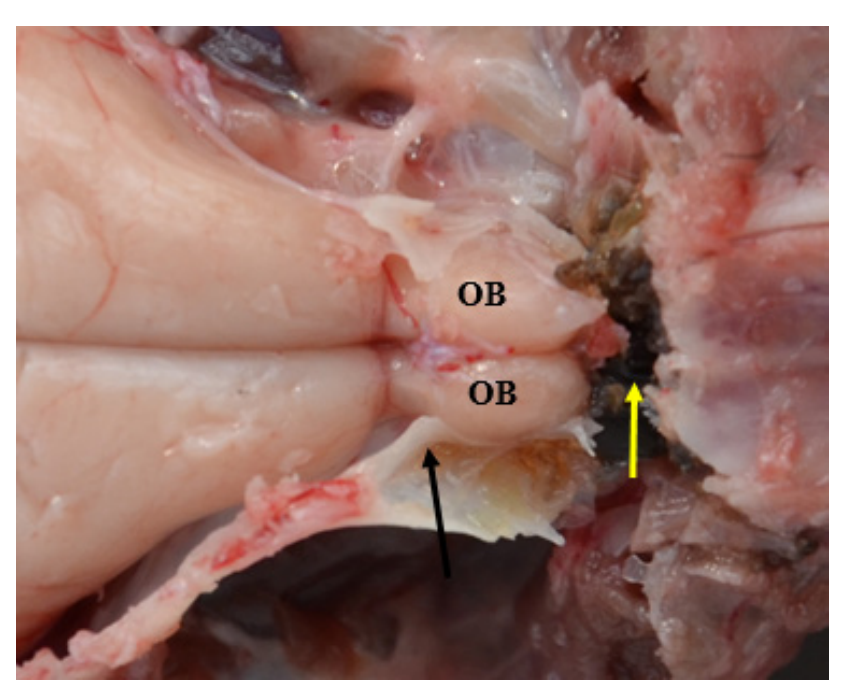

Fig. 1. Dorsal view of the olfactory bulbs (OB) in situ showing the demarcation between the olfactory fossa and the cranial cavity (back arrow) and the aboral segment of the ethmoid bone (yellow arrow).
The dorsal side of each bulb presented a pronounced convex profile. While the body of the bulb was completely uncovered by the frontal lobes, lowering the attached bulb allowed us to notice that latero-aborally to the dorsal surface of the bulb, there was a small tubercle separated by a circular groove, corresponding to an accessory olfactory bulb (Fig.4). Topographically, this element was hidden by the ventral side of the anterior pole of the cerebral hemisphere.

The histological coronal samples presented a laminar structure with several layers from the surface to the center of the bulb (Fig. 5). The first outer layer was identified as the olfactory nerve layer; the lack of pigment indicated that it is unmyelinated. Its width did not present itself as uniform perimeter, being thinner on the dorsal aspect and thickest in the ventro-lateral and medial sides. The second layer possessed a particular aspect, composed of multiple ovoid structures or varying diameter corresponding to the glomerular layer. The third layer was also well developed, but displayed a lower cell density - the external plexiform layer. Towards the interior, however the cell density rose again, presenting a well visible ribbon of large neuron somata (mitral cells) corresponding to the mitral cell layer. Subjacent to this, a thin inner plexiform layer was visible, presenting, similar to its external counterpart a lower density of cellular somata.

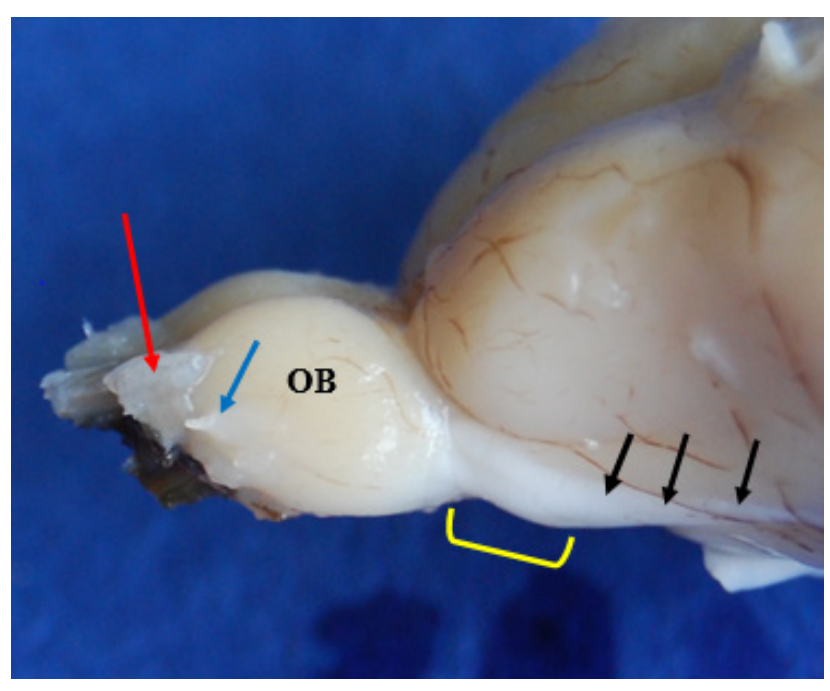

Fig. 2. Lateral view of the olfactory bulb (OB) with fragment of the cribriform plate (red arrow), fragment of olfactory fascicle (blue arrow), olfactory peduncle (yellow indicator) and lateral olfactory stria (black arrows). 
The core of the bulb corresponded to the granule cell layer containing small neurons (granule cells). In the middle of the granule cell layer, there is also a ribbon of sudependymal layer.

Very early on the rostral-aboral axis, a single layer of ependymal cells also appears within the subependymal layer, denoting the existence of a reduced olfactory ventricle (Fig.6A). Also, progressing caudally towards the peduncle, in the last third of the olfactory bulbs, on the dorso-

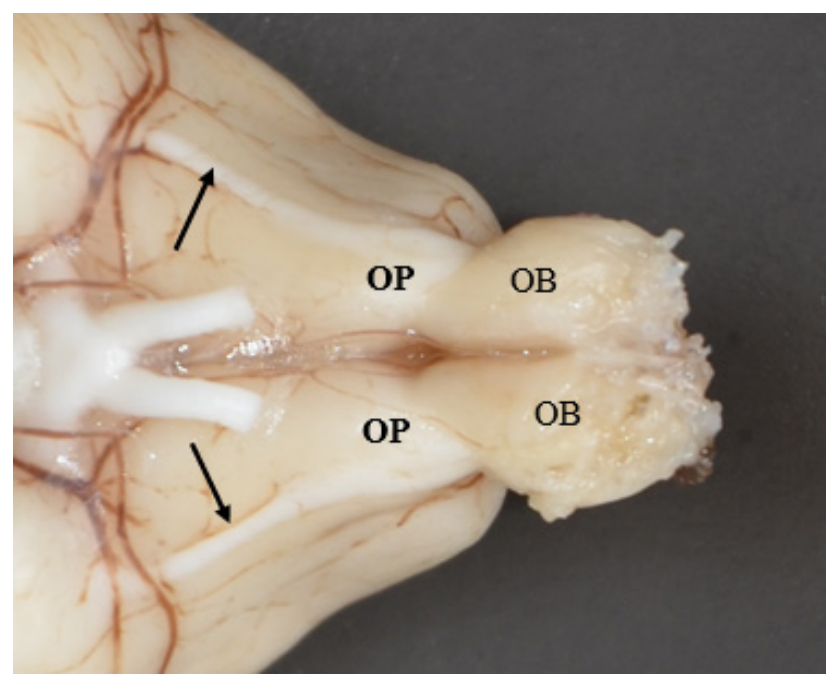

Fig. 3. Ventral view of the olfactory bulbs (OB), the olfactory peduncle (OP), olfactory lateral striae (black arrows).

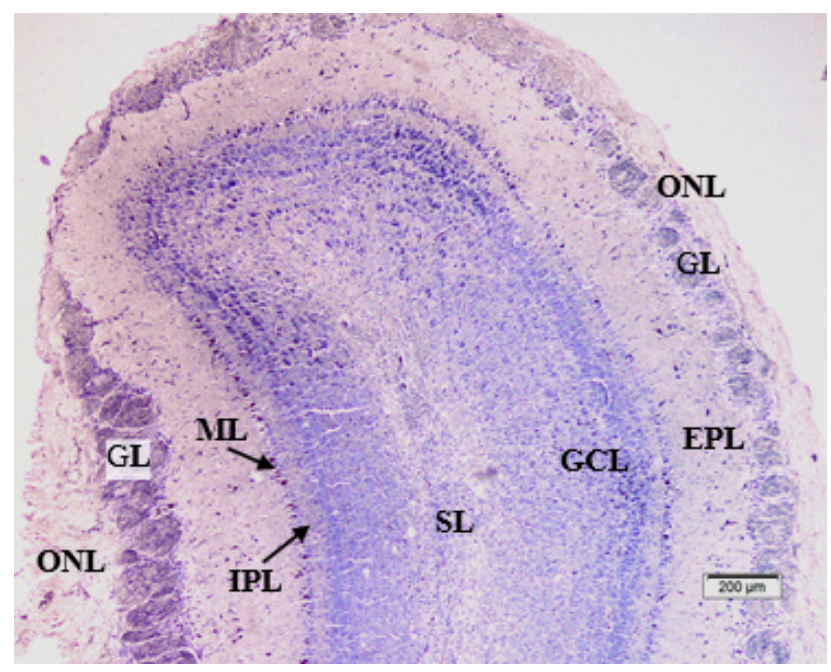

Fig. 5. Laminar structure of the olfactory bulb: olfactory nerve layer (ONL); glomerular layer (GL); external plexiform layer (EPL); mitral cell layer (ML); inner plexiform layer (IPL); granule cell layer (GCL); subependymal layer (SL) (Luxol-Cresyl stain). lateral aspect of the coronal cuts the following layers appear: unmyelinated nerve fascicles entering a thinner glomerular layer, and a mitral cell layer separating a thicker external layer and a smaller inner plexiform layer. The granular layer is less highlighted, separated from the former by the fascicles belonging to the lateral olfactory tract. The presence of this histological structure dorsolaterally to the incipient olfactory peduncle, attests the existence of the accessory olfactory bulb.

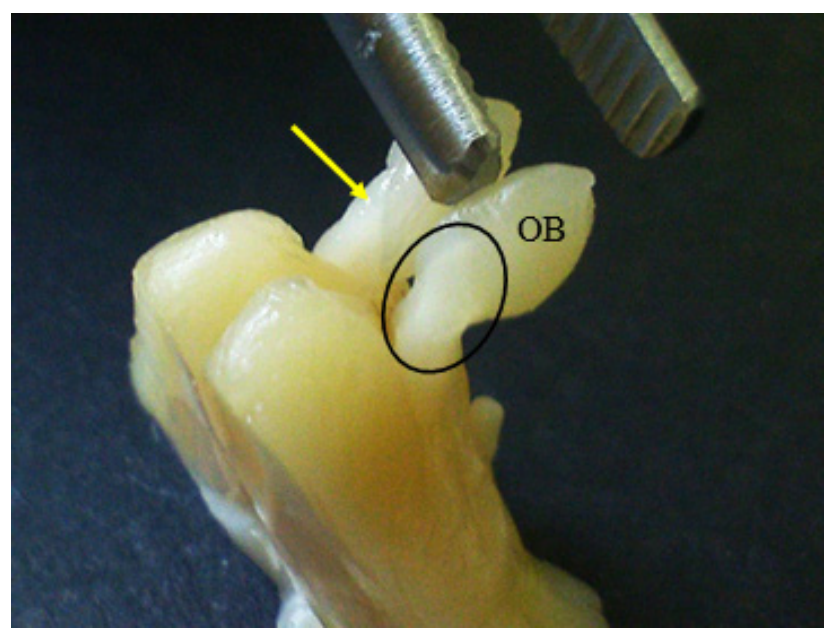

Fig. 4. Dorsal aspect of the olfactory bulbs (OB), with accessory olfactory bulbs (left one - yellow arrow, right one - black circle).

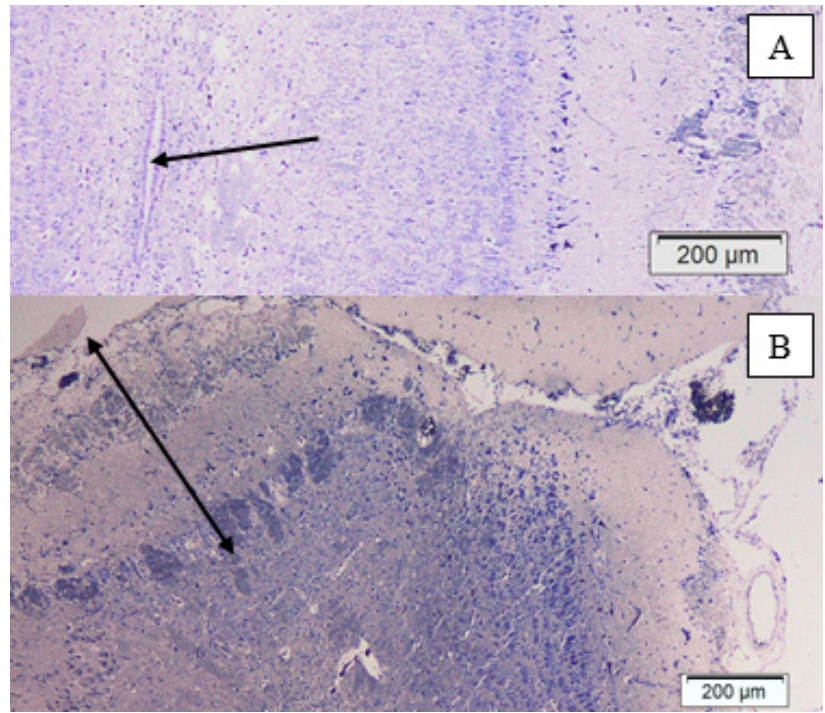

Fig. 6. Structural details: (A) presence of the ependymal layer and the olfactory ventricle (black arrow); (B) accessory olfactory bulb (black arrow) (Luxol-Cresyl stain). 
The large volume of the olfactory bulbs in chinchillas, as well as the existence of the accessory olfactory bulbs indicates that this species is a macrosmatic one, which is a common trait shared by Rodents and Lagomorphs (Shipley, 2004; Barone and Bortolami, 2004). While the general aspect of the chinchilla's bulbs and its adjacent elements corresponds to literature descriptions (Damian, 2011; Popovici, 2000), there are certain noticeable differences between this species and the main Glires members used as laboratory animals. The main olfactory bulbs are proportionally smaller in chinchillas than in rats, when compared to the overall aspect of the encephalon. Rabbits have more elongated olfactory bulbs continued by longer peduncles well beyond the limit of the frontal lobes (Barone and Bortolami, 2004) than in the chinchillas, thus the accessory olfactory bulbs are visible in the former, and hidden by the frontal cortex in the latter. The topography of the accessory bulbs also differ slightly between the chinchilla and the rat: in the former, this element is placed latero-dorsally to the bulb; in the latter it has a more dorsal and rostral placement (Shipley, 2004).

With regard to the laminar histological structure of the C. lanigera's olfactory bulbs, its layers correspond to the descriptions in literature of this segments in rats (Shipley, 2004; Paxinos and Watson, 2007) and in rabbits (Barone and Bortolami, 2004), but some micromorphological differences to the rat can be noticed such as: the glomerules in the chinchilla have a less homogenous aspect than in the rat and their size is overall smaller (Shipley indicates variations of $60-180 \mu$ in glomerular size in the rat, while chinchillas present a average range of $40-150 \mu$ ). Also, considering the seriate coronal sections, the granular layer of the accessory bulbs has a more uniform peripheral placement in chinchillas, while in the rats it has a more early central placement on the sections (Paxinos and Watson, 2007); the olfactory ventricle also registers a more oral and appearance in the rat with a more prominent lumen (Paxinos and Watson, 2007), while in chinchillas it is placed more aborally and the lumen is elongated dorso-ventrally and very narrow.

\section{CONCLUSION}

The proportionally well developed olfactory bulbs, as well as the existence of the accessory olfactory bulbs demonstrates that C. lanigera is a macrosmatic species. Their gross anatomy features and their laminar histological structure correspond to literature descriptions in rats and rabbits. However, certain particularities have been highlighted, concerning elements such as: the dorso-rostral topography of the accessory bulbs, the anterior reach on the olfactory ventricle topography, the irregularity of the glomerules' micromorphology and their wider size variation.

\section{REFERENCES}

1. Alworth LC, Harvey SB (2012). Anatomy, Physiology, and Behavior. In: Mark A Suckow, Karla A Stevens and Ronald P Wilson (eds). The Laboratory Rabbit, Guinea Pig, Hamster, and Other Rodents, Academic Press, Boston, 955-966.

2. Barone R, Bortolami R (2004). Anatomie Comparee des mammiferes domestiques, Tome 6, Neurologie I, Systeme nerveux central. Vigot, Paris, 7-43.

3. Bennett ET (1835). On the Chinchillidae, a family of herbivorous Rodentia, and on a new genus referrible [sic] to it. Transactions of the Zoological Society of London 1:35-64. Cited in: Spotorno AE., Zuleta CA, Valladares JP, Deane AL and Jimenez JE (2004). Chinchilla laniger, Mammalian Species, 758:1-9.

4. Brent JM (2012). Taxonomy and History - Part V: Chinchillas. In : Mark A Suckow, Karla A Stevens and Ronald P Wilson (eds). The Laboratory Rabbit, Guinea Pig, Hamster, and Other Rodents, Academic Press, Elsevier Inc, 949-953.

5. Damian A (2011). Anatomia sistemului nervos central. AcademicPres, Cluj-Napoca, 5-10,14-67.

6. Eggermont JJ (2015). Animal models of auditory temporal processing. International Journal of Psychophysiology 95(2): 202-215.

7. Frisina RD, Zettel ML, Kelley PE, Walton JP (1995). Distribution of calbindin D-28k immunoreactivity in the cochlear nucleus of the young adult chinchilla. Hearing Research me 85(1-2):53-68.

8. Godfrey DA, Godfrey MA, Ding DL, Chen K, Salvi RJ (2005). Amino acid concentrations in chinchilla cochlear nucleus at different times after carboplatin treatment. Hearing Research 206(1-2):64-73.

9. Guan, Xiying, Yongzheng Chen, Rong Z Gan (2014). Factors affecting loss of tympanic membrane mobility in acute otitis media model of chinchilla. Hearing Research 309:136-146.

10. Heffner RS, Heffner HE (1991). Behavioral hearing range of the chinchilla. Hearing Research 52(1):13-16.

11. Hrapkiewicz K, Mendina L, Holmes DD (1998). Chichillas. In : Hrapkiewicy K, Medina L, Holmes DD (edit). Clinical Medicine of Small Mammals and Primates - an introduction, $2^{\text {nd }}$ edition, Manson Publishing, London, 117-132.

12. Irimescu I, Bolfa PF, Vidrighinescu R, Crisan MI, Dezdrobitu CC, Damian A (2014a). Preliminary results 
of a macroscopical and histological study of the medulla oblongata in chinchillas (Chinchilla lanigera). Anatomia, Histologia, Embryologia 43(1):54

13. Irimescu I, Chende A, Ghiurco F, Damian A (2014c). Anatomical Study of the Cerebral Hemispheres in the Chinchilla (Chinchilla lanigera). Bulletin of UASVM 71(1):130-136.

14. Irimescu I, Crisan MI, Dezdrobitu CC, Damian A (2014b). Preliminary results of a macroscopical study of the cerebral hemispheres in chinchillas (Chinchilla lanigera). Anatomia, Histologia, Embryologia 43(1):55.

15. Irimescu I, Damian A, Chende A, Ghiurco F, Csibi D (2012). Anatomical study of the brainstem of the chinchilla. Proceedings of the XXIXth Congress of the EAVA, Stara Zagora, Bulgaria, BJVM 15(1):29.

16. Jackson BS, Relkin EM (1998). A frequency-dependent saturation evident in rate-intensity functions of the chinchilla auditory nerve. Hearing Research 126(1-2):7583.

17. Jaworska-Adamu JA, Szalak R (2009). Parvalbumin And Calbindin D28k In The Dorsal Raphe Nucleus Of The Chinchilla. Bull Vet Inst Pulawy 53:791-7944.

18. Jimenez, JE (1996). The Extirpation and Current Status of Wild Chinchilla Chichilla lanigera and C. brevicaudata. Biological Conservation 77(1):1-6.

19. Kraus KS, Ding D, Jiang H, Kermany MH, Mitra S, Salvi RJ (2013). Up-regulation of GAP-43 in the chinchilla ventral cochlear nucleus after carboplatin-induced hearing loss: Correlations with inner hair cell loss and outer hair cell loss. Hearing Research 302:74-82.

20. Martin L (2012). Chinchillas as Experimental ModelsPart V: Chinchillas. In: Mark A Suckow, Karla A Stevens and Ronald P Wilson (eds). The Laboratory Rabbit, Guinea Pig, Hamster, and Other Rodents, Academic Press, Elsevier Inc, 1009-1028.

21. Mohlis C (1983). Informacion primar sobre la conservacion y manejo de la chinchilla silvestre en Chile. Boletin Tecnico 3, Corporacion National Forestal, Santiago.

22. Montúfar-Chaveznava R, Hernández-Campos O, Hudson R, Caldelas I (2012). Differential maturation of the molecular clockwork in the olfactory bulb and suprachiasmatic nucleus of the rabbit. Neuroscience 207:198-207.

23. Mousa AM, Shehab AA (2015). The effect of manganese on the olfactory bulb of adult male albino rat and the role of meloxicam: A histological and immunohistochemical study. Journal of Microscopy and Ultrastructure 3(1):8-18.

24. Paxinos G, Watson C (2007). The Rat Brain in Stereotaxic Coordinates. 6th edition, Academic Press, Elsevier Inc, Burlington.

25. Popovici I, Damian A, Papuc I (2000). Anatomie comparată. Sistemul nervos și endocrine. AcademicPres, Cluj-Napoca, 7-77.

26. Qing Liu, Anan Li, Ling Gong, Lei Zhang, Nan Wu, Fuqiang Xu (2013). Decreased coherence between the two olfactory bulbs in Alzheimer's disease model mice. Neuroscience Letters 545:81-85.

27. Shipley MT, Ennis M, Puche AC (2004). Chapter 29 Olfactory System. In: Paxinos G (ed). The Rat Nervous System, 3rd edition, Academic Press, Elsevier Inc, San Diego, California, 923-964.

28. Shun Chen, Hong-yu Tan, Zhuo-hua Wu, Chong-peng Sun, Jian-xun He, Xin-chun Li, Ming Shao (2014). Imaging of olfactory bulb and gray matter volumes in brain areas associated with olfactory function in patients with Parkinson's disease and multiple system atrophy. European Journal of Radiology 83(3):564-570.

29. Spotorno AE, Zuleta CA, Valladares JP, Deane AL, Jimenez JE (2004). Chinchilla laniger. Mammalian Species 758:1-9.

30. Stekelorom-Parmentelat MD (2006). Le Chinchilla, nouvel animal de compagnie. These, Ecole Nationale Veterinaire de Lyon, 15-18.

31. Szalak R, Jaworska-Adamu J (2011). Intracellular expression of selected calcium-binding proteins in the neurons of a chinchillas hippocampus. Medycyna Wet 67(10):695-699.

32. Zhong Z, Henry KS, Heinz MG (2014). Sensorineural hearing loss amplifies neural coding of envelope information in the central auditory system of chinchillas. Hearing Research 309:55-62. 